\title{
Gas chromatographic isolation of individual compounds from complex matrices for radiocarbon dating
}

TI Eglinton

LI Alueihare

JE Bauer

Virginia Institute of Marine Science

ERM Druffel

AP McNichol

Follow this and additional works at: https://scholarworks.wm.edu/vimsarticles

Part of the Analytical Chemistry Commons

\section{Recommended Citation}

Eglinton, Tl; Alueihare, LI; Bauer, JE; Druffel, ERM; and McNichol, AP, Gas chromatographic isolation of individual compounds from complex matrices for radiocarbon dating (1996). Analytical Chemistry, 68(5), 904-912.

$10.1021 / \operatorname{ac} 9508513$

This Article is brought to you for free and open access by the Virginia Institute of Marine Science at W\&M ScholarWorks. It has been accepted for inclusion in VIMS Articles by an authorized administrator of W\&M ScholarWorks. For more information, please contact scholarworks@wm.edu. 


\title{
Gas Chromatographic Isolation of Individual Compounds from Complex Matrices for Radiocarbon Dating
}

\author{
Timothy I. Eglinton* and Lihini I. Aluwihare \\ Department of Marine Chemistry and Geochemistry, Woods Hole Oceanographic Institution, \\ Woods Hole, Massachusetts 02543 \\ J ames E. Bauer \\ School of Marine Science, College of William and Mary, Gloucester Point, Virginia 23062 \\ Ellen R. M. Druffel \\ Department of Earth System Science, University of California Irvine, Irvine, California 92717
}

Ann P. McNichol

National Ocean Sciences Accelerator Mass Spectrometry Facility, Woods Hole Oceanographic Institution, Woods Hole, Massachusetts 02543

This paper describes the application of a novel, practical approach for isolation of individual compounds from complex organic matrices for natural abundance radiocarbon measurement. This is achieved through the use of automated preparative capillary gas chromatography (PCGC) to separate and recover sufficient quantities of individual target compounds for ${ }^{14} \mathrm{C}$ analysis by accelerator mass spectrometry (AMS). We developed and tested this approach using a suite of samples (plant lipids, petroleums) whose ages spanned the ${ }^{14} \mathrm{C}$ time scale and which contained a variety of compound types (fatty acids, sterols, hydrocarbons). Comparison of individual compound and bulk radiocarbon signatures for the isotopically homogeneous samples studied revealed that $\Delta^{14} \mathrm{C}$ values generally agreed well $( \pm 10 \%)$. B ackground contamination was assessed at each stage of the isolation procedure, and incomplete solvent removal prior to combustion was the only significant source of additional carbon. Isotope fractionation was addressed through compound-specific stable carbon isotopic analyses. Fractionation of isotopes during isolation of individual compounds was minimal $\left(<5 \%\right.$ ofor $\left.\delta^{13} \mathrm{C}\right)$, provided the entire peak was collected during PCGC. Trapping of partially coeluting peaks did cause errors, and these results highlight the importance of conducting stable carbon isotopic measurements of each trapped compound in concert with AMS for reliable radiocarbon measurements. The addition of carbon accompanying derivatization of functionalized compounds (e.g., fatty acids and sterols) prior to chromatographic separation represents a further source of potential error. This contribution can be removed using a simple isotopic mass balance approach. Based on these preliminary results, the PCGC-based approach holds promise for accurately determining ${ }^{14} \mathrm{C}$ ages on compounds specific to a given source within complex, heterogeneous samples.
Radiocarbon dating is an important analytical tool in a variety of disciplines from archeology to environmental chemistry. ${ }^{1-3}$ This is because the halflife of ${ }^{14} \mathrm{C}$ is convenient for investigating processes over climatically and anthropologically relevant time scales, and because ${ }^{14} \mathrm{C}$ is integrally associated with the carbonaceous phases which play a pivotal role in biological and geological processes. M any studies of natural samples (soils, sediments, atmospheric particles, archeological remnants) encounter isotopically and chemically heterogeneous matrices which complicate ${ }^{14} \mathrm{C}$-based age determinations. In oceanography, for example, a major application of ${ }^{14} \mathrm{C}$ is in dating of sedimentary organic matter $(\mathrm{OM})$ for calculation of sediment accumulation rates and delineation of time horizons. ${ }^{4,5}$ For these purposes, the radiocarbon content of bulk organic carbon $(\mathrm{OC})$ is assumed to reflect that of autochthonous primary biological production in the overlying water column. A major uncertainty in these OC-based measurements is the unknown proportion of reworked (i.e., ${ }^{14} \mathrm{C}$ age less than contemporary) carbon within the sediment. ${ }^{5}$ Bulk level radiocarbon measurements of $\mathrm{OC}$ mask any isotopic heterogeneity within the sample. Attempts have been made to determine ${ }^{14} \mathrm{C}$ ages of purified subfractions of sedimentary $\mathrm{OM},{ }^{6-9}$ but it is still not possible to directly equate these ages with a specific source. Such isotopic diversity may only be fully expressed at the

(1) Currie, L. A.; Stafford, T. W.; Sheffield, A. E.; Klouda, G. A.; Wise, S. A.; Fletcher, R. A.; Donahue, D. J.; J ull, A. J. T.; Linick, T. W. Radiocarbon 1989, $31,448$.

(2) Druffel, E. R. M.; Williams, P. M. Mar. Chem. 1992, 39, 209.

(3) Stafford, T. W., J r.; Hare, P. E.; Currie, L.; Jull, A. J. T.; Donahue, D. J. J. Archaeol. Sci. 1991, 18, 35.

(4) Calvert, S. E.; Karlin, R. E.; Toolin, L. J.; Donahue, D. J.; Southon, J. R.; Vogel, J. S. Nature 1991, 350, 692.

(5) Jones, G.; Gagnon A. Deep Sea Res. 1994, 41, 531

(6) Simoneit, B. R. T. Mar. Chem. 1977, 5, 443.

(7) Lowe, J. J.; Lowe, S.; F owler, A. J.; Hedges, R. E. M .; Austin, T. J. F. Boreas 1988, 17, 355.

(8) Giger, W.; Sturm, M.; Sturm, H.; Schaffner, C.; Bonani, G.; Balzer, R.; Hofmann, H. J.; M orenzoni, E.; Nessi, M .; Suter, M.; Wölfli, W. Nucl. Instrum. M ethods Phys. Res. 1984, B5, 394.

(9) Watchman, A. Aust. J. Earth Sci. 1994, 41, 179. 


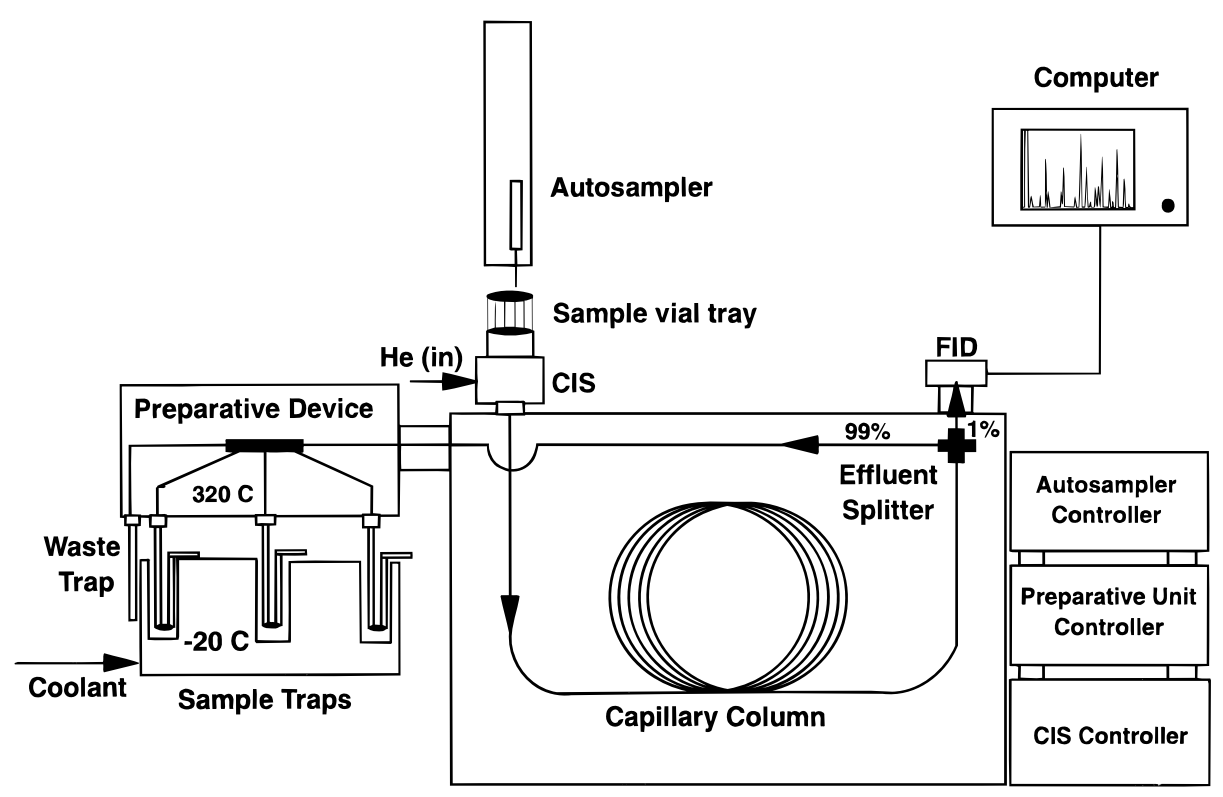

Gas Chromatograph

Figure 1. Diagrammatic representation of the PCGC instrument.

molecular level, ${ }^{3}$ where ${ }^{14} \mathrm{C}$ ages can be tied to individual compounds whose structures indicate an unequivocal link to a known precursor.

M olecular level ${ }^{14} \mathrm{C}$ analysis at natural abundance levels is not a new concept, and results have been obtained in isolated cases. 1,3,10 However, it is thus far not a routine procedure and has not been applied to sedimentary or other complex mixtures comprising bulk organic materials of interest in the ocean sciences and related disciplines. Several technical challenges present themselves before compound-specific radiocarbon analysis (CSRA) can be realized. Foremost among these is the low natural abundance of ${ }^{14} \mathrm{C}\left(\sim 1\right.$ part in $\left.10^{12}\right)$ in biologically derived samples. The advent of accelerator mass spectrometry (AM S) has greatly reduced sample size requirements. ${ }^{11,12}$ In general, however, $\geq 100$ $\mu \mathrm{g}$ of $\mathrm{C}$ is often required for accurate and precise ${ }^{14} \mathrm{C}$ measurements. ${ }^{13,14}$ In addition, the complexity of the mixtures which comprise sedimentary and other natural forms of $O M$ is formidable. Typically, hundreds to thousands of individual compounds are present even within purified subfractions. Separation of compounds in high purity, therefore, demands the resolving power of capillary gas chromatography (GC). However, conventional capillary GC has limited sample capacity ( $<500 \mathrm{ng} /$ compound) and thus far has not been practical for isolation of sufficient quantities of individual compounds for $A M S{ }^{14} \mathrm{C}$ analysis.

To overcome these limitations, we have developed and applied a novel analytical approach using automated preparative capillary gas chromatography $\left(\mathrm{PCGC}^{15}\right)$ to isolate sufficient quantities of pure individual compounds for natural abundance ${ }^{14} \mathrm{C}$ measurement. Our ultimate goal is to determine radiocarbon contents of compounds that are specific for different sources. This paper describes the methodology and results obtained on a series of

(10) van Klinken, G. J.; Bowles, A. D.; Hedges, R. E. M. Geochim. Cosmochim. Acta 1994, 58, 2543.

(11) Hedges, R. E. M.; Gowlett, J. A. J. Sci. Am. 1986, 254, 100.

(12) Vogel, J. S.; Turteltaub, K. W.; Finkel, R.; N elson, D. E. Anal. Chem. 1995, $67,353 \mathrm{~A}$.

(13) Vogel, J. S.; Nelson, D. E.; Southon, J. R. Radiocarbon 1987, 29, 323.

(14) Vogel, J. S.; Nelson, D. E.; Southon, J. R. Radiocarbon 1989, 31, 145.

(15) Rijks, P. E. M.; Rijks, J. A. J. High Resolut. Chromatogr. 1990, 13, 261. test materials of varying ${ }^{14} \mathrm{C}$ ages and discusses potential applications in the environmental and natural sciences.

\section{EXPERIMENTAL SECTION}

PCGC System Description. The PCGC system used is shown in Figure 1. The system consists of a Hewlett Packard 5890 Series II gas chromatograph, equipped with a flame ionization detector (FID) and a HP 7673 autoinjector, integrated with a Gerstel cooled injection system (CIS), a zero-dead-volume effluent splitter, and a preparative trapping device. The preparative device consists of an eight-port zero-dead-volume valve in a heated interface $\left(\sim 300{ }^{\circ} \mathrm{C}\right)$ and seven $200-\mu \mathrm{L}$ glass U-tube traps (six sample traps and a waste trap) supported in liquid nitrogen-cooled $\left(-20{ }^{\circ} \mathrm{C}\right)$ units. The autoinjector, $\mathrm{CIS}$, and trapping device are programmable and microprocessor controlled, and FID data are acquired using Chromperfect software. Compounds were separated using a 15- or 30-m "megabore" ( $0.53 \mathrm{~mm}$ i.d.) fused silica capillary column coated with a cross-bonded methylsilicone phase $\left(R_{T X-1,}\right.$, Restek; film thickness, $\left.0.5 \mu \mathrm{m}\right)$. With the exception of the Agave americana sample, for which pyridine was used, all samples were run in hexane as solvent.

Sample and Compound Selection. Reference materials chosen for the development stage of this project are listed in Table 1. These samples were selected to cover a range of radiocarbon contents and yield a variety of compound classes representative of the types encountered in geochemical samples.

Two pristine high-wax petroleum samples (Hibernia, Nova Scotia; Green River, Utah, approximately 150 and 50 million years old, respectively) were selected as an abundant source of hydrocarbons (primarily n-alkanes and isoprenoid alkanes) with an infinite radiocarbon age (i.e., $\Delta^{14} \mathrm{C} \approx-1000 \%$. At the other end of the age spectrum, two living plant samples (Crassula argentea and Agave americana) were analyzed to provide endmembers with "modern" radiocarbon ages. The leaf waxes of the C. argentea sample, obtained locally from a commercial greenhouse, were dominated by $C_{27}-C_{33} n$-alkanes. In contrast, the $A$. americana sample, collected from La Jolla, CA, yielded predominantly fatty acids and sterols. For a reference material of 
Table 1. Materials Selected for Analysis

\begin{tabular}{|c|c|c|c|c|c|c|c|c|c|c|}
\hline sample & type & age & $\begin{array}{l}\text { compound } \\
\text { type(s) }\end{array}$ & $\delta^{13} C_{\text {TOC }(\%)^{a}}$ & $A M S^{b}$ & log no. & $\Delta^{14} C_{\text {TOC }\left(\% q^{c}\right.}$ & $\Delta^{14} C$ error & $\begin{array}{c}{ }^{14} \mathrm{C} \text { age } \\
(\mathrm{y}))^{\mathrm{d}}\end{array}$ & $\begin{array}{l}{ }^{14} \mathrm{C} \\
\text { age error }\end{array}$ \\
\hline $\begin{array}{l}\text { Hibernia } \\
\text { Green River } \\
\text { A. americana } \\
\text { C. argentea } \\
\text { Egyptian tomb vase } \\
\text { methanol } \\
\text { BSTFA } \\
C_{21} \text { fatty acid }\end{array}$ & $\begin{array}{l}\text { petroleum } \\
\text { petroleum } \\
\text { plant leaf } \\
\text { plant leaf } \\
\text { viscous oil } \\
\text { reagent } \\
\text { reagent } \\
\text { internal std }\end{array}$ & $\begin{array}{l}\sim 150 \times 10^{6} \mathrm{y} \\
\sim 50 \times 10^{6} \mathrm{y} \\
\text { modern } \\
\text { modern } \\
1498 \text { B.C. }{ }^{e}\end{array}$ & $\begin{array}{l}\text { alkanes } \\
\text { alkanes } \\
\text { fatty acids, sterols } \\
\text { alkanes } \\
\text { fatty acids } \\
\text { nag } \\
\text { na } \\
\text { fatty acid }\end{array}$ & $\begin{array}{l}-25.7 \\
-31.5 \\
-14.8 \\
-23.9 \\
-26.5 \\
-51.3 \\
-37.4 \\
-26.5\end{array}$ & $\begin{array}{l}\text { LLNL } \\
\text { LLNL } \\
\text { LLNL } \\
\text { LLNL } \\
\text { WHOI } \\
\text { WHOI } \\
\text { WHOI } \\
\text { LLNL }\end{array}$ & $\begin{array}{l}11628 \\
15257 \\
15256 \\
15252 \\
\text { OS-3177 } \\
\text { OS-4355 } \\
\text { OS-4406 } \\
15259\end{array}$ & $\begin{array}{r}-1000 \\
-998 \\
+98 \\
-113 \\
-345 \\
-992 \\
-1000 \\
+366\end{array}$ & $\begin{array}{r} \pm 1 \\
\pm 1 \\
\pm 7 \\
\pm 10 \\
\pm 4 \\
\pm 1 \\
\pm 1 \\
\pm 10\end{array}$ & $\begin{array}{l}>51700 \\
>43000 \\
\text { modern } \\
960 \\
3360 \\
39300 \\
>49000 \\
\text { modern }\end{array}$ & $\begin{array}{r} \pm 90 \\
\pm 50 \\
\pm 1100\end{array}$ \\
\hline
\end{tabular}

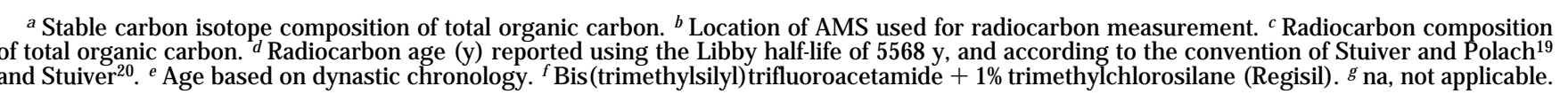

intermediate age, we obtained a sample of oil from an alabaster vessel recovered from an Egyptian grave independently dated at 1498 B.C. The oil was comprised largely of free and esterified mono- and dicarboxylic acids.

Lipid fractions were isolated from the plant tissue samples by Soxhlet or ultrasonic extraction using $\mathrm{CH}_{3} \mathrm{OH}$ and $\mathrm{CHCl}_{3}$. The extracts were combined, dried over anhydrous $\mathrm{Na}_{2} \mathrm{SO}_{4}$, reduced to dryness by rotary evaporation, and redissolved in $\mathrm{CH}_{2} \mathrm{Cl}_{2}$. For samples used as a source of hydrocarbons (petroleums, $\mathrm{C}$. argentea extract), an aliphatic hydrocarbon fraction of the oil or extract was obtained by flash chromatography ${ }^{16}$ using activated silica as adsorbant and hexane as eluant. Extracts from A. americana and Egyptian oil samples were transesterified using $\mathrm{CH}_{3} \mathrm{OH} / \mathrm{HCl}\left(95: 5 \mathrm{v} / \mathrm{v}, 70{ }^{\circ} \mathrm{C}, 12 \mathrm{~h}\right.$ under $\left.\mathrm{N}_{2}\right)$ to hydrolyze bound fatty acids and form corresponding methyl esters. For the A. americana sample, a further derivatization step (Regisil in pyridine) was performed to silylate alcohols (sterols).

All solvents were Burdick and Jackson "GC2" grade. All glassware was acid-cleaned in Nochromix solution and rinsed with distilled $\mathrm{H}_{2} \mathrm{O}, \mathrm{CH}_{3} \mathrm{OH}, \mathrm{CH}_{2} \mathrm{Cl}_{2}$, and hexane prior to use.

Conversion of Trapped Samples to Graphite Targets for AMS. After PCGC isolation, the $U$-tubes containing the trapped components were detached, and the contents were recovered by addition of $\mathrm{CH}_{2} \mathrm{Cl}_{2}(1 \mathrm{~mL})$ and transferred to 2-mL glass ampules. An aliquot ( 50 or $100 \mu \mathrm{L}$ ) was removed and transferred to a $\mathrm{GC}$ autosampler vial (for determination of purity, yield, and stable carbon isotopic composition). Each ampule was flame-sealed and stored at $4{ }^{\circ} \mathrm{C}$ prior to target preparation for AMS. To combust the sample, the ampule's contents were transferred to quartz combustion tubes $(20 \mathrm{~cm} \times 7$ or $9 \mathrm{~mm}$ o.d.). Solvent was removed under a stream of high-purity nitrogen or helium, and CuO $(\sim 2$ $\mathrm{mg} / \mu \mathrm{g}$ of $\mathrm{C}$ ) was added. As a precaution to remove any residual solvent, the sample tube was evacuated to $10^{-6}$ Torr while immersed in a dry ice/ 2-propanol bath. The bath was replaced by liquid nitrogen, and the quartz tube was flame-sealed under vacuum. The tubes were then heated at $850-900^{\circ} \mathrm{C}$ for $5 \mathrm{~h}$, and the resulting $\mathrm{CO}_{2}$ was purified, quantified, and reduced to graphite according to standard procedures. ${ }^{17,18}$ Graphite targets were pressed and prepared according to established procedures for radiocarbon analysis by $\mathrm{AMS} .{ }^{14} \mathrm{C}$ measurements were made at either the Center for Accelerator M ass Spectrometry (CAMS) at

(16) Still, W. C.; Kahn, M.; M itra, A. J. Org. Chem. 1978, 43, 2923.

(17) Vogel, J. S.; Southen, J. R.; N elson, D. E. Nucl. Instrum. M ethods Phys. Res. 1987, B29, 50.

(18) M cNichol, A. P.; Gagnon, A. R.; Jones, G. A.; Osborne, E. A. Radiocarbon $1992,34,321$.
Lawrence Livermore National Laboratory (LLNL) or at the National Ocean Sciences Accelerator Mass Spectrometry (NOSAMS) facility at Woods Hole Oceanographic Institution (WHOI). The principles of AM S were recently described by Vogel and co-workers, ${ }^{12}$ and radiocarbon data are reported as $\Delta^{14} \mathrm{C}(\%)$ and ${ }^{14} \mathrm{C}$ age according to established conventions. ${ }^{19,20}$

Supplemental Analyses. High-Resolution Capillary GC and GC/MS. Initial mixtures and aliquots of isolated compounds were analyzed by high-resolution capillary GC(HRGC) to determine compound concentrations and purities. The HRGC consisted of a HP 5890 Series II GC equipped with a HP 7673 autoinjector, an on-column injector, electronic pressure control, and an FID. Compounds were separated on a $\&$ W DB-1 column $(60 \mathrm{~m} \times 0.32$

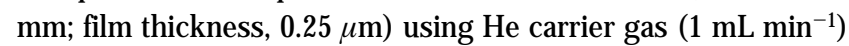
and a temperature program from $50^{\circ} \mathrm{C}$ (initial hold time, $0 \mathrm{~min}$ ) to $320^{\circ} \mathrm{C}$ at a rate of $6^{\circ} \mathrm{C} \mathrm{min}^{-1}$. Samples were dissolved in either hexane or dichloromethane, and a $0.5-\mu \mathrm{L}$ injection volume was used. Data were acquired and integrated using Chromperfect software.

Compound identities and purities were confirmed by GC/MS analysis. GC/ M S was performed using a HP 5890 GC, equipped as above, interfaced to a VG Autospec-Q mass spectrometer. Chromatographic conditions were identical to those used for HRGC (with vacuum compensation). Spectra were scanned over the range 50-600 amu, with a cycle time of $1 \mathrm{~s}$. Electron impact ionization (EI) at $50 \mathrm{eV}$ was used for all analyses.

I sotope Ratio M onitoring Gas Chromatography/ M ass Spectrometry. Stable carbon isotopic compositions of mixtures and of isolated compounds were determined by isotope ratio monitoring gas chromatography/ mass spectrometry (irm-GC/M S). ${ }^{21-23}$ Instrumental conditions were nearly identical to those reported by Hayes and co-workers ${ }^{21}$ and by Goñi and Eglinton. ${ }^{23}$ Gas chromatographic conditions were as follows: on-column injection onto a $50-\mathrm{m} \times 0.32-\mathrm{mm}$-i.d. fused silica column coated with methylsilicone $(0.5 \mu \mathrm{m}, \mathrm{HP}$ Ultra- 1$)$, temperature programmed from $35^{\circ} \mathrm{C}$ (initial hold time, $10 \mathrm{~min}$ ) to $320^{\circ} \mathrm{C}$ (final hold time, $25 \mathrm{~min}$ ) at $3{ }^{\circ} \mathrm{C} \mathrm{min}^{-1}$. Helium was used as carrier gas.

${ }^{13} \mathrm{C} /{ }^{12} \mathrm{C}$ values were calibrated against those of deuterated n-alkane internal isotopic standards (co-injected with the sample) as well as external $\mathrm{CO}_{2}$ gas standards. All isotopic compositions

(19) Stuiver, M.; Pollach, H. A. Radiocarbon 1977, 19, 355.

(20) Stuiver, M. Radiocarbon 1980, 22, 964.

(21) Hayes, J. M .: Freeman, K. H.; Popp, B. N. Org. Geochem. 1990, 16, 1115.

(22) Ricci, M. P.; M erritt, D. A.; Freeman, K. H.; Hayes, J. M. Org. Geochem. 1994, 21, 561.

(23) Goñi, M. A.; Eglinton, T. I. J. High Resolut. Chromatogr. 1994, 17, 476. 
are reported relative to the Pee Dee B elemnite (PDB) carbonate reference material.

Bulk Isotopic Analyses. Stable carbon isotopic compositions for the bulk samples were determined by either sealed-tube (liquids) or automated on-line combustion (solids), followed by conventional isotope ratio mass spectrometry (Finnigan Delta-S mass spectrometer). Details of both procedures are given by Fry and co-workers. ${ }^{24}$ Samples for bulk ${ }^{14} \mathrm{C}$ measurements were prepared in an identical fashion to that used for the trapped compounds.

\section{RESULTS AND DISCUSSION}

The preparative capillary gas chromatography (PCGC) system, recently developed by Gerstel GmbH, Mülheim a.d. Ruhr, Germany, is designed specifically for high-resolution separation and enrichment of individual organic compounds. Although this technique has been successfully applied to other analytical problems ${ }^{25}$ this study represents the first attempt to use PCGC for the isolation of compounds for radiocarbon analysis. The major components of the instrument, illustrated in Figure 1, are a hybrid of a conventional autosampler and GC (H ewlett Packard) integrated with a programmable cooled injection system (CIS), splitter valves, and a cryogenic collection device (Gerstel). Preparative scale yields of individual compounds within mixtures are obtained by repeated sample injections, followed by chromatographic separation and selective cryogenic trapping.

Several features make this approach ideal for collection of individual compounds for ${ }^{14} \mathrm{C}$ analysis. First, the autosampler and $\mathrm{CIS}$ allow precise, repeated injections of samples as large as 25 $\mu \mathrm{L}$. The CIS accommodates these large volumes by using an independent temperature program to induce "solvent elimination", i.e., venting of solvent, prior to transferring the sample to the chromatographic column. ${ }^{15}$ The septumless head on the CIS also removes the possibility that leaks will form due to repeated puncture of a septum. The large samples are separated on a highcapacity "megabore" ( $0.53 \mathrm{~mm}$ i.d.) capillary GC column. The GC is temperature programmed, and, upon separation, the eluting components pass through a zero-dead-volume effluent splitter arranged to deliver $<1 \%$ of the flow to an FID and $>99 \%$ to the preparative trapping device via a heated transfer line. The FID permits monitoring of the column effluent throughout the course of the chromatographic run and facilitates delineation of trapping time windows for the selected analytes.

The heart of the preparative trapping device is a zero-deadvolume eight-port valve. The direction of effluent flow through this multiport valve is back-pressure controlled by solenoid valves located after the traps-a configuration which minimizes the potential for contamination. The valves are microprocessor controlled, enabling specification of precise time slices. Up to 50 time slices can be collected in any given trap, permitting, for example, collection of related compounds as a single, composite sample. M icroprocessor control of the autosampler, CIS, GC, and preparative device allows synchronized injection, separation, and trapping of target compounds from multiple runs. Preliminary tests revealed that, using wide-bore, thick-film capillary columns, it is possible to isolate purified compounds from mixtures at concentrations approaching $5 \mu \mathrm{g}$ of a single compound per

(24) Fry, B.; Brand, W.; M ersch, F. J.; Tholke, K.; Garrit, R. Anal. Chem. 1992, 64, 288.

(25) M acNamara, K. Proc. Int. Sci. Symp. Cognac., 1st (Cantagrel, R., Ed.) 1992, 385.

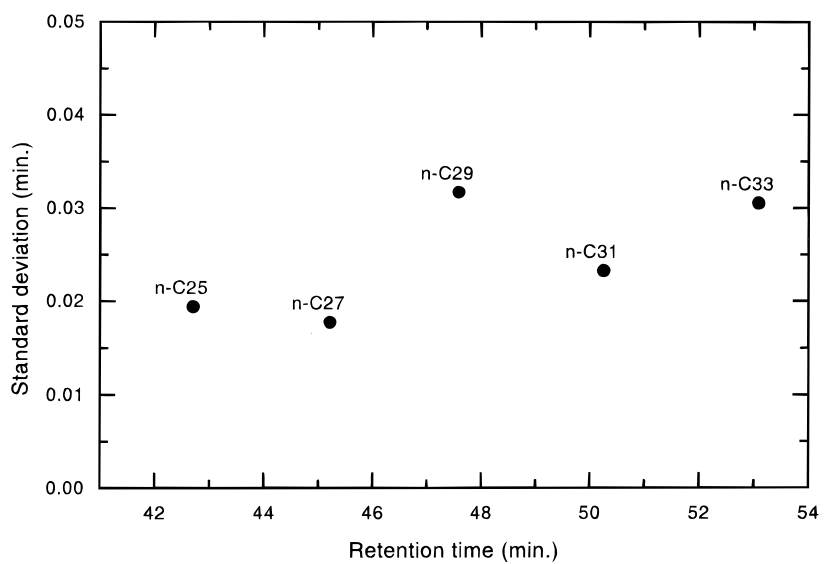

Figure 2. Variation in retention times, expressed as standard deviation (in minutes), for selected $n$-alkanes from 22 replicate PCGC runs. Sample: Crassula argentea hexane fraction.

injection. ${ }^{26} \mathrm{M}$ ore than 50 repeated runs are usually required to collect sufficient quantities of material for AMS.

The reproducibility of retention times is illustrated for selected alkanes from a sequence of PCGC runs of the $C$. argentea sample in Figure 2. In general, retention times do not shift by more than a few seconds within a 70-min run cycle. Trapping times can thus be defined within narrow tolerances.

Trapping Efficiency. Results for the trapping of $n$-alkanes from an aliphatic hydrocarbon fraction of the Eocene-age Green River petroleum sample are illustrated in Figure 3 and Table 2. In addition, a chromatographic "blank" (a portion of the chromatogram where baseline values were observed) was trapped. Figure 4 shows HRGC traces of aliquots from several of the trapped components (recovered after dissolution in $\mathrm{CH}_{2} \mathrm{Cl}_{2}$ ). Yields and trap windows are listed in Table 2. As shown in Figure 4 , the selected analytes were cleanly isolated from the mixture despite the slightly inferior resolution of the PCGC column. M oreover, estimated yields exceeded $200 \mu \mathrm{g} C$ in some cases, well within minimum requirements for ${ }^{14} \mathrm{C}$ analysis by AMS. The products which accumulated in the waste trap (trap 0) were also recovered and rechromatographed (Figure 4). The resulting GC trace clearly illustrates the efficiency with which compounds of interest can be isolated from such complex mixtures. Here, distinct gaps in the homologous series of $n$-alkanes indicate where specific compounds were removed and recovered in one of the six sample traps. Although it is not possible to be precise because sample loadings vary somewhat throughout a PCGC run series, in most cases we estimate trapping recovery efficiencies (i.e., the amount of compound recovered from the trap relative to the total amount injected) to be $>80 \%$ for compounds with boiling points below $320^{\circ} \mathrm{C}$.

A similar example is shown for the Egyptian oil sample in Figure 5. In this case, the selected analytes were a series of fatty acids (as methyl esters), including a $\mathrm{C}_{21}$ fatty acid internal standard added to the mixture prior to esterification. The HRGC traces of aliquots from the resulting traps again illustrate the purity of the trapped compounds. In these and other examples, clean trapping of target compounds is evident, and yields are in many cases in excess of $100 \mu \mathrm{g}$ of $\mathrm{C}$ (Table 2), with compound purities often exceeding $90 \%$ (based on GC peak area integration). The only

(26) Aluwihare, L. I. Summer Student Fellow Dissertation, Woods Hole Oceanographic Institution, Woods Hole, M A, 1993. 


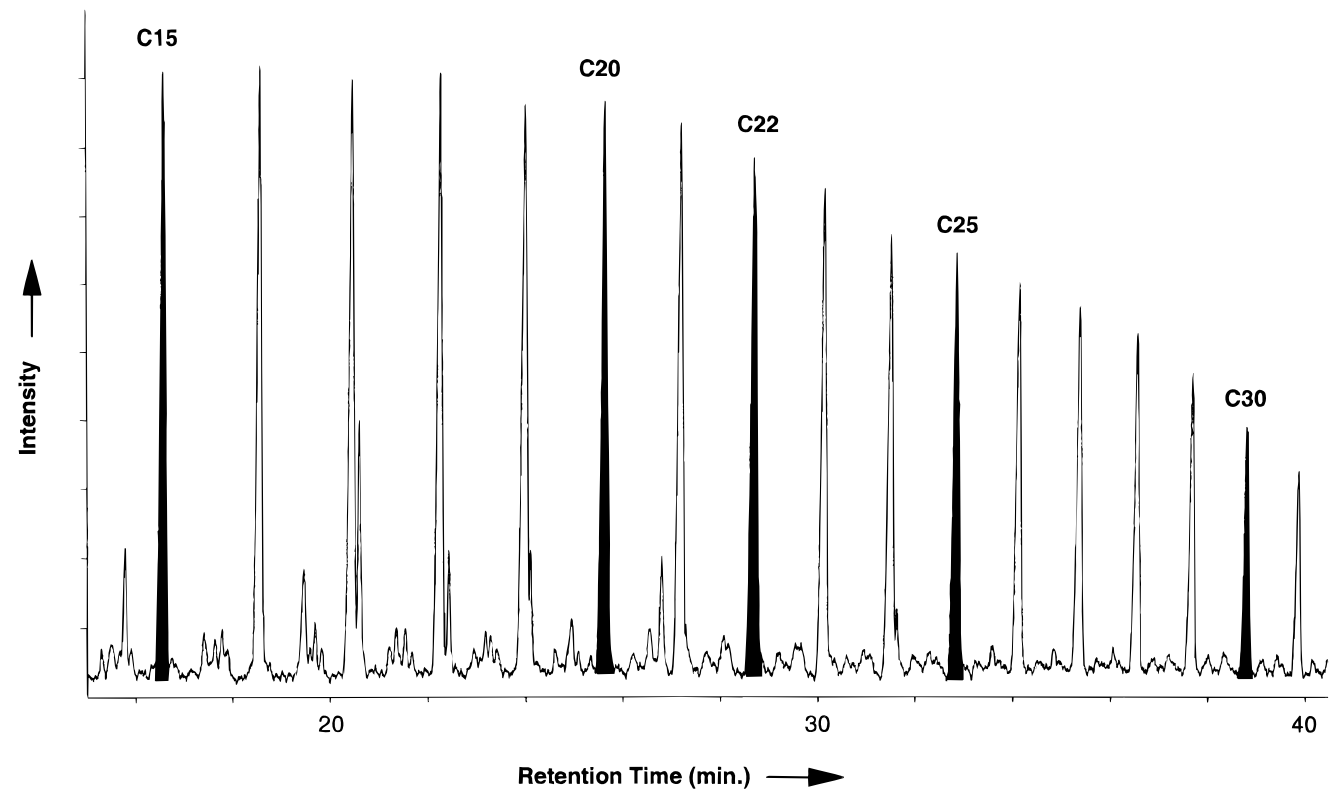

Figure 3. Partial PCGC trace of Green River petroleum (hexane fraction). Shaded areas indicate compounds selected for isolation. GC and trapping conditions as in Experimental Section.

Table 2. PCGC, irm-GC/MS, and AMS Results

\begin{tabular}{|c|c|c|c|c|c|c|c|c|c|c|c|c|c|c|}
\hline \multirow[b]{2}{*}{ sample } & \multirow{2}{*}{$\begin{array}{l}\text { target } \\
\text { compound }\end{array}$} & \multirow[b]{2}{*}{ identity } & \multirow[b]{2}{*}{$i n j^{a}$} & \multirow{2}{*}{$\begin{array}{l}\text { trap window } \\
(\min )\end{array}$} & \multirow{2}{*}{$\begin{array}{c}\text { yield } \\
\text { HRGC } \\
(\mu \mathrm{g} \mathrm{C})^{b}\end{array}$} & \multicolumn{2}{|c|}{$\delta^{13} \mathrm{C}(\%)^{\mathrm{c}}$} & \multirow[b]{2}{*}{ AM S } & \multirow[b]{2}{*}{ log no. } & \multirow{2}{*}{$\begin{array}{c}\text { yield } \\
\mathrm{CO}_{2} \\
(\mu \mathrm{g})^{d}\end{array}$} & \multirow{2}{*}{$\Delta^{14} \mathrm{C}(\%)^{\mathrm{e}}$} & \multirow{2}{*}{$\begin{array}{c}\Delta^{14} C_{\text {corr }} \\
(\%)^{\dagger}\end{array}$} & \multirow[b]{2}{*}{${ }^{14} \mathrm{C}$ age $(\mathrm{y})^{\mathrm{e}}$} & \multirow{2}{*}{$\begin{array}{l}{ }^{14} \mathrm{C} \\
\text { age }_{\text {corr }}{ }^{\mathrm{f}}\end{array}$} \\
\hline & & & & & & init & trap & & & & & & & \\
\hline reen River & $\begin{array}{l}n-C_{15} \text { alkane } \\
n-C_{20} \text { alkane } \\
n-C_{22} \text { alkane } \\
n-C_{25} \text { alkane } \\
n-C_{30} \text { alkane }\end{array}$ & $\begin{array}{l}a \\
b 1^{g} \\
b 2^{g} \\
c \\
d \\
e\end{array}$ & $\begin{array}{l}113 \\
113 \\
113 \\
113 \\
113 \\
113\end{array}$ & $\begin{array}{l}16.00-17.00 \\
25.18-26.05 \\
25.18-26.05 \\
28.35-29.07 \\
32.45-33.15 \\
38.45-39.00\end{array}$ & $\begin{array}{r}273 \\
305 \\
305 \\
310 \\
270 \\
62\end{array}$ & $\begin{array}{l}-30.5 \\
-32.7 \\
-32.7 \\
-32.5 \\
-32.8 \\
-32.7\end{array}$ & $\begin{array}{l}-33.5 \\
-31.8 \\
-31.8 \\
-32.2 \\
-32.3 \\
-32.8\end{array}$ & $\begin{array}{l}\text { WHOI } \\
\text { LLNL } \\
\text { LLNL } \\
\text { LLNL } \\
\text { WHOI }\end{array}$ & $\begin{array}{l}\text { OS-4360 } \\
14893 \\
14894\end{array}$ & $\begin{array}{c}126 \\
142 \\
195 \\
\mathrm{nd}^{\mathrm{h}} \\
309 \\
126\end{array}$ & $\begin{array}{l}-992 \pm 1 \\
-993 \pm 3 \\
-995 \pm 3 \\
\text { nd } \\
-997 \pm 3 \\
-993 \pm 1\end{array}$ & $\begin{array}{l}\text { nah } \\
\text { na } \\
\text { na } \\
\text { na } \\
\text { na } \\
\text { na }\end{array}$ & $\begin{array}{l}39300 \pm 740 \\
40350 \pm 3670 \\
42420 \pm 4360 \\
\text { nd } \\
46170 \pm 7610 \\
40300 \pm 1300\end{array}$ & $\begin{array}{l}\text { na } \\
\text { na } \\
\text { na } \\
\text { na } \\
\text { na } \\
\text { na }\end{array}$ \\
\hline C. argentea & $\begin{array}{l}\mathrm{n}-\mathrm{C}_{29} \text { alkane } \\
\mathrm{n}-\mathrm{C}_{31} \text { alkane } \\
\mathrm{n}-\mathrm{C}_{33} \text { alkane } \\
\mathrm{n}-\mathrm{C}_{31} \text { alkane }\end{array}$ & $\begin{array}{l}\mathrm{f} \\
\mathrm{g} 1^{g} \\
\mathrm{~g} 2^{g} \\
\mathrm{~h} \\
\mathrm{i}\end{array}$ & $\begin{array}{l}90 \\
90 \\
90 \\
90 \\
75\end{array}$ & $\begin{array}{l}37.14-38.00 \\
39.31-40.38 \\
39.31-40.38 \\
41.40-42.20 \\
39.40-40.40\end{array}$ & $\begin{array}{r}21 \\
358 \\
358 \\
12 \\
304\end{array}$ & $\begin{array}{l}-34.0 \\
-38.1 \\
-38.1 \\
-40.4 \\
-38.1\end{array}$ & $\begin{array}{l}-34.7 \\
-36.8 \\
-36.8 \\
-39.5 \\
-36.4\end{array}$ & $\begin{array}{l}\text { LLNL } \\
\text { LLNL } \\
\text { WHOI }\end{array}$ & $\begin{array}{l}15250 \\
15251 \\
\text { OS-4361 }\end{array}$ & $\begin{array}{r}\text { nd } \\
270 \\
140 \\
\text { nd } \\
385\end{array}$ & $\begin{array}{c}\text { nd } \\
-186 \pm 6 \\
-196 \pm 5 \\
\text { nd } \\
-178 \pm 5\end{array}$ & $\begin{array}{l}\text { na } \\
\text { na } \\
\text { na } \\
\text { na } \\
\text { na }\end{array}$ & $\begin{array}{c}\text { nd } \\
1650 \pm 70 \\
1750 \pm 60 \\
\text { nd } \\
1530 \pm 55\end{array}$ & $\begin{array}{l}\text { na } \\
\text { na } \\
\text { na } \\
\text { na } \\
\text { na }\end{array}$ \\
\hline A. americana & $\begin{array}{l}C_{16: 0} \text { fatty acid } \\
C_{18: 1} \text { fatty acid } \\
C_{29: 1} \text { sterol }\end{array}$ & $\begin{array}{l}j \\
k \\
\text { l }\end{array}$ & $\begin{array}{l}84 \\
84 \\
84\end{array}$ & $\begin{array}{l}20.34-21.16 \\
23.00-23.90 \\
38.80-39.50\end{array}$ & $\begin{array}{r}133 \\
290 \\
58\end{array}$ & $\begin{array}{l}-28.3 \\
-27.6 \\
-22.6\end{array}$ & $\begin{array}{l}-29.1 \\
-22.9 \\
-22.5\end{array}$ & $\begin{array}{l}\text { WHOI } \\
\text { LLNL } \\
\text { LLNL }\end{array}$ & $\begin{array}{l}\text { OS-4356 } \\
14896 \\
14897\end{array}$ & $\begin{array}{r}98 \\
195^{i} \\
84\end{array}$ & $\begin{aligned}-32 & \pm 6 \\
-3 & \pm 6 \\
-66 & \pm 10\end{aligned}$ & $\begin{array}{l}+28 \\
+53 \\
+30\end{array}$ & $\begin{aligned} 260 & \pm 50 \\
0 & \pm 50 \\
550 & \pm 90\end{aligned}$ & $\begin{array}{l}\text { modern } \\
\text { modern } \\
\text { modern }\end{array}$ \\
\hline Egyptian oil & $\begin{array}{l}C_{16: 0} \text { fatty acid } \\
C_{18: 1} \text { fatty acid } \\
C_{21: 0} \text { fatty acid } \\
C_{16: 0} \text { fatty acid } \\
C_{18: 1} \text { fatty acid } \\
\text { unknown } \\
\text { unknown } \\
C_{21: 0} \text { fatty acid }\end{array}$ & $\begin{array}{l}m \\
n \\
o \\
p \\
q \\
r \\
s \\
t\end{array}$ & $\begin{array}{l}58 \\
58 \\
58 \\
59 \\
59 \\
59 \\
59 \\
59\end{array}$ & $\begin{array}{l}25.70-26.35 \\
28.31-29.16 \\
33.15-33.84 \\
23.55-24.40 \\
26.25-27.07 \\
27.73-28.26 \\
28.50-29.10 \\
31.11-31.86\end{array}$ & $\begin{array}{r}73 \\
181 \\
33 \\
379 \\
460 \\
40 \\
31 \\
281\end{array}$ & $\begin{array}{l}-26.5 \\
-24.1 \\
-27.2 \\
-26.5 \\
-24.1 \\
-27.9 \\
-26.2 \\
-27.2\end{array}$ & $\begin{array}{l}-28.7 \\
-27.8 \\
-29.9 \\
-27.4 \\
-26.6 \\
-29.0 \\
-27.5 \\
-29.9\end{array}$ & $\begin{array}{l}\text { LLNL } \\
\text { LLNL } \\
\text { LLNL } \\
\text { WHOI } \\
\text { WHOI } \\
\text { WHOI } \\
\text { WHOI } \\
\text { WHOI }\end{array}$ & $\begin{array}{l}14900 \\
14899 \\
14898 \\
\text { OS-4359 } \\
\text { OS-4362 } \\
\text { OS-4353 } \\
\text { OS-4354 } \\
\text { OS-4358 }\end{array}$ & $\begin{array}{r}102 \\
182 \\
52 \\
264 \\
409 \\
61 \\
63 \\
160\end{array}$ & $\begin{array}{l}-393 \pm 4 \\
-376 \pm 5 \\
+193 \\
-335 \pm 4 \\
-355 \pm 6 \\
-346 \pm 8 \\
-387 \pm 8 \\
+311 \pm 12\end{array}$ & $\begin{array}{l}-355 \\
-341 \\
+252 \\
-293 \\
-319 \\
-309 \\
-353 \\
+373\end{array}$ & $\begin{array}{l}4007 \pm 60 \\
3796 \pm 70 \\
\text { modern } \\
3280 \pm 50 \\
3530 \pm 80 \\
3410 \pm 95 \\
3940 \pm 110 \\
\text { modern }\end{array}$ & $\begin{array}{l}3522 \\
3350 \\
\text { modern } \\
2795 \\
3094 \\
2979 \\
3506 \\
\text { modern }\end{array}$ \\
\hline
\end{tabular}

a Total number of consecutive PCGC runs performed. ${ }^{b}$ Determined by response relative to an $n-C_{28}$ alkane external standard. ${ }^{c} D$ etermined by irm-GC/M S. d Determined after sealed-tube combustion. e Radiocarbon concentration and age (yrs B.P.) reported using the Libby half-life of 5568 $y$, and according to the convention of Stuiver and Polach ${ }^{19}$ and Stuiver. ${ }^{20}$ Sample preparation backgrounds have been substracted, based on measurements of samples of ${ }^{14} \mathrm{C}$-free coal. Backgrounds were scaled relative to sample size. ${ }^{f}$ Radiocarbon measurements corrected for the presence of derivative carbon (Egyptian oil and A. americana samples only). ${ }^{9}$ Compounds isolated by PCGC were split prior to combustion and analyzed as separate samples to provide duplicate measurements. ${ }^{h}$ nd, not determined; na, not applicable. ${ }^{i} 50 \%$ of sample combusted.

exception is the A. americana sample, from which the traps dedicated to $\mathrm{C}_{16: 0}$ and $\mathrm{C}_{18: 1}$ fatty acids clearly contained more than one component. High-resolution GC/M S analysis of the original mixture and trapped products revealed that the $C_{18: 1}$ peak contained a second unsaturated $\mathrm{C}_{18}$ fatty acid which was not resolved during PCGC. In the case of the $C_{16: 0}$ fatty acid, the trapping window had been too wide, and the trap consequently included an earlier eluting peak. Excluding these cases, our first objective of isolating sufficient quantities of compound for AMS was realized.
Isotopic Fractionation Effects. An initial concern with respect to the PCGC approach was the potential for isotopic fractionation as a result of the isolation procedure. Potential points at which fractionation may occur are during CIS injection, at the effluent splitter and multiport valve, and in the cryogenic traps, but the most likely cause of fractionation would be incomplete peak isolation. These effects were tested and, to some degree, corrected for using stable carbon isotopic measurements.

The recent advent of on-line irm-GC/ M S allows stable carbon isotopic analysis of small quantities $(\sim 10-100 \mathrm{ng}$ of $\mathrm{C})$ of specific 


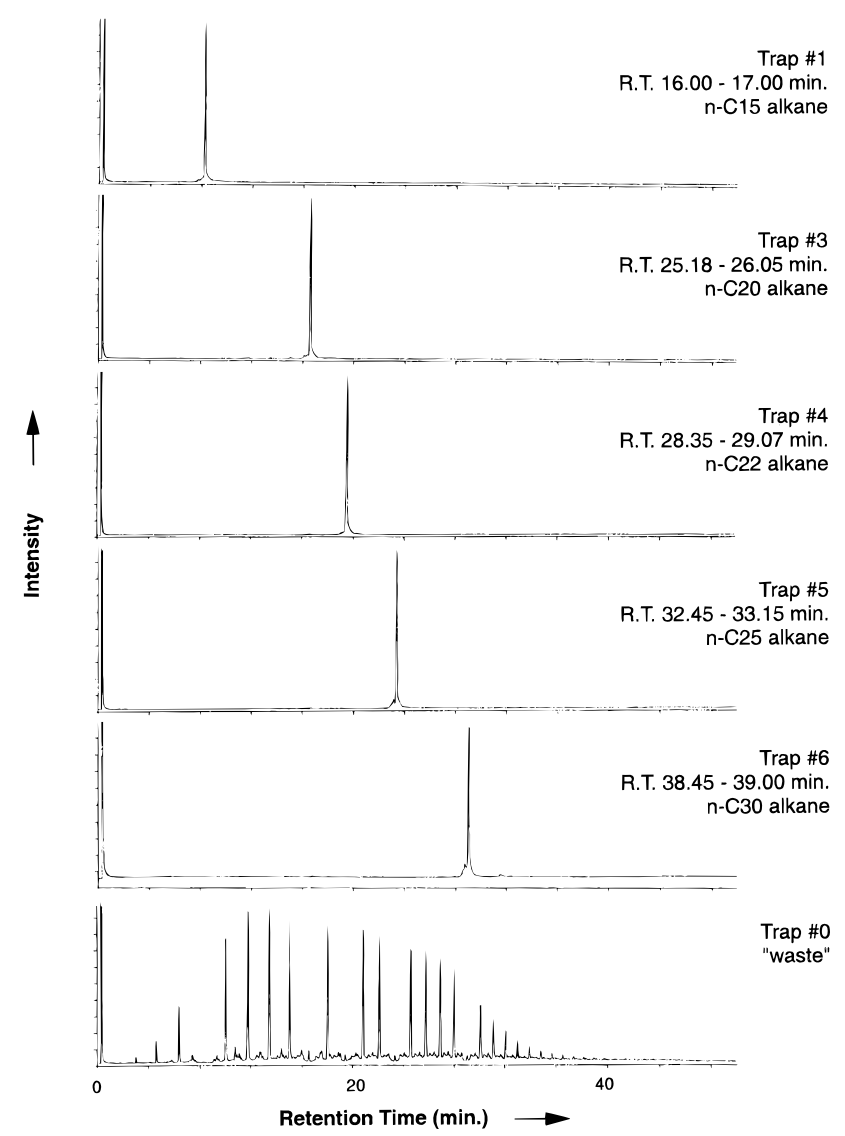

Figure 4. HRGC traces of Green River trapped products collected from 113 PCGC runs. The traces represent chromatograms for aliquots of the product(s) in each trap. Trap 0 represents accumulation of components other than those selected for isolation.

compounds. From irm-GC/M S studies, ${ }^{21}$ it has been observed that there is a temporal separation of the ${ }^{13} \mathrm{C}$ and ${ }^{12} \mathrm{C}$ isotopes during chromatography. Since a similar effect would be expected for ${ }^{14} \mathrm{C}$, it was anticipated that isotopic fractionation would be observed if an analyte were incompletely collected (i.e., if the trapping window did not include the full width of the peak, particularly leading or tailing portions that were isotopically enriched or depleted).

To examine the effects of incomplete collection, alkanes from the Hibernia petroleum sample were separated and isolated by PCGC. In this case, 54 repeated PCGC runs were performed, and peaks trapped included those due to the $n-C_{15}$ and $n-C_{17}$ alkanes and 2,6,10,14-tetramethylpentadecane (pristane), which partially coelutes ( $\sim 30 \%$ valley) with the latter $n$-alkane. Trapping times were set to collect $n-C_{17}$ and pristane separately, with the switch occurring at the base of the valley. The partial coelution on the PCGC column leads to the appearance of the more abundant component $\left(n-C_{17}\right)$ in both traps (Figure 6). Stable carbon isotopic compositions were determined for $n-C_{17}(-29.1 \%$ ) and pristane (-29.2\% in the original mixture, as well as in each trap. In the " $n-C_{17}$ trap" n- $C_{17}$ was $1.4 \%$ enriched in ${ }^{13} C$, whereas the portion of the same compound which was carried over into the "pristane" trap was $9.4 \%$ odepleted in ${ }^{13} \mathrm{C}$ compared to that in the original mixture. This fractionation is consistent with predicted as well as known chromatographic behavior of carbon isotopes, in which apolar columns induce earlier elution of molecules containing the heavier isotope. ${ }^{21,27}$ This effect is apparent in Figure 6 as a characteristic inflection or "isotopic

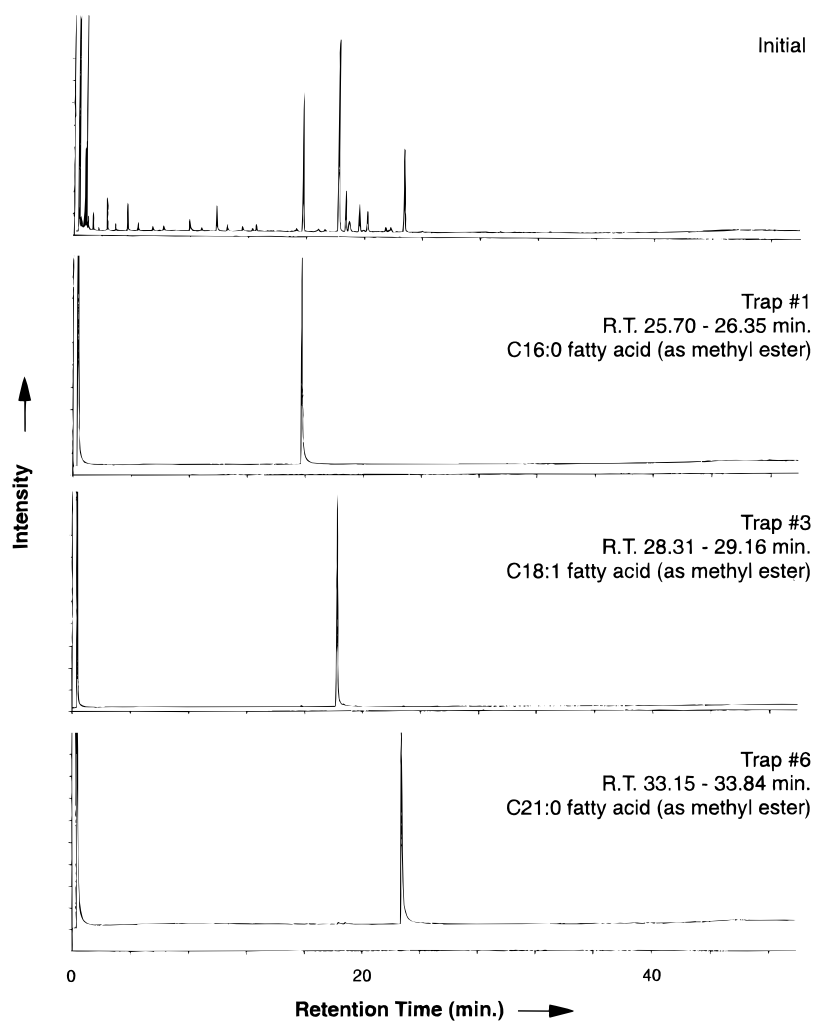

Figure 5. HRGC traces of transesterified Egyptian oil trapped products isolated by PCGC (no. of runs $=58$ ). Top trace shows initial mixture before PCGC. See Figure 4 legend for further explanation.

swing" on the mass $45 / 44$ ratio trace from irm-GC/M S22,23. Notably, the $\delta$ value for pristane, which was apparently trapped more completely, is virtually identical to that within the original mixture.

These results indicate that isotopic fractionation can, indeed, occur as a result of PCGC separation. Any fractionation in the ${ }^{14} \mathrm{C} /{ }^{12} \mathrm{C}$ ratio would be twice that observed for the ${ }^{13} \mathrm{C} /{ }^{12} \mathrm{C}$ ratio. ${ }^{19}$ However, provided the trap window encompasses the entire peak, this effect should be negligible. Table 2 and Figure 7 show stable carbon isotopic compositions for each target compound both before and after isolation. In the majority of cases, the $\delta$ values agree to within 1-2\%o with the largest deviation being $5 \%$ Comparison of these stable carbon isotopic $\delta$ values thus serves as a useful quality control indicator for subsequent ${ }^{14} \mathrm{C}$ data.

Radiocarbon Measurements. The samples selected for this study contain compounds that are also found in geochemical materials. We chose these samples because, by virtue of their origin and history, it was probable that individual compounds isolated from the organic matter would have the same ${ }^{14} \mathrm{C}$ age as the bulk OM. In this way, we hoped to establish whether compounds isolated by PCGC would faithfully record the radiocarbon content of their parent material.

Table 2 lists the ${ }^{14} \mathrm{C}$ results from AMS analysis of trapped compounds. Excluding potential errors associated with AMS measurements of small sample sizes or isotopic fractionation effects, our primary concern was the presence and magnitude of any contaminating carbon introduced into the samples at various stages of processing. It is our current estimate that the minimum

(27) van Hook, W. A. In Isotope effects in chemical processes; Gould, R. F., Ed.; ACS Advances in Chemistry Series 69; American Chemical Society: Washington, DC, 1969; p 99. 
(a) Initial
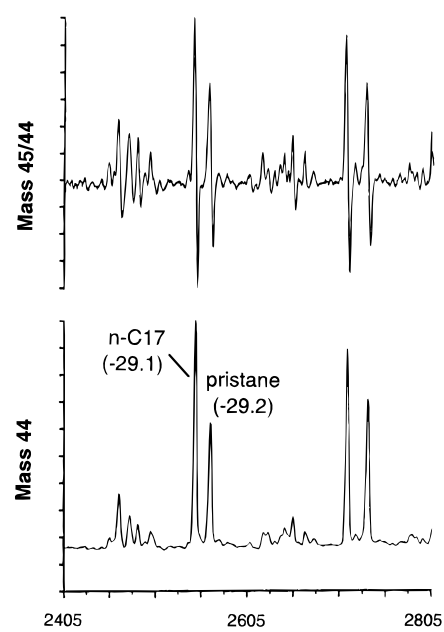

(b) "n-C17" trap
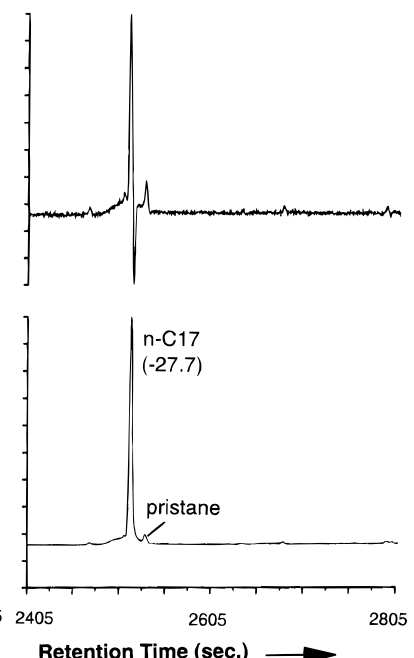

(c) "pristane" trap
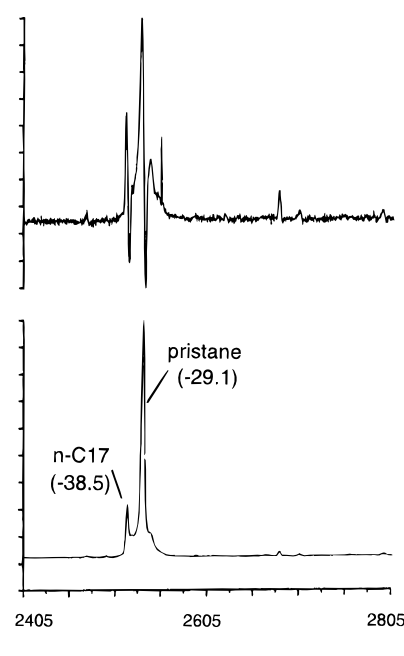

Figure 6. Irm-GC/MS of Hibernia petroleum hydrocarbons: (a) total (hexane) fraction, (b) " $n-C_{17}$ trap" products, and (c) "pristane trap" products. Lower traces are mass 44 partial chromatograms; upper traces are partial chromatograms of mass $45 / 44$ ratio. " $n$ - $C_{17}$ " denotes $C_{17} n$-alkane; "pristane" denotes 2,6,10,14-tetramethylpentadecane.

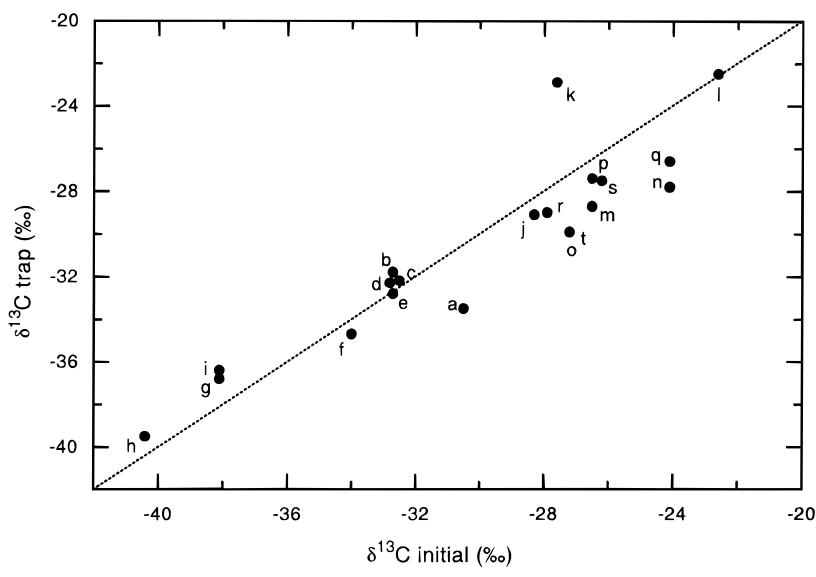

Figure 7. Comparison between $\delta^{13} \mathrm{C}$ values (\%。 relative to PDB standard), determined from irm-GC/MS of selected compounds before and after isolation by PCGC. See Table 2 for compound identifications.

contamination deriving from the combustion of the sample through to its measurement is $\sim 2 \mu \mathrm{g}$ of "modern equivalent" carbon, having an isotope ratio of $1.2 \times 10^{-12}{ }^{14} \mathrm{C} /{ }^{12} \mathrm{C}$. It is likely, however, that the added processing through the PCGC system could significantly increase the background contamination. The PCGC approach does have an advantage in that any contamination of the sample prior to separation by PCGC will not interfere with ${ }^{14} \mathrm{C}$ results unless the contaminant(s) coelutes with the compounds of interest. However, once the target compound has been isolated and trapped in the U-tube, great care must be taken to avoid contamination during manipulation of the sample prior to AMS analysis.

Two potentially significant sources of contamination were identified (excluding those due to working in an unclean environment): column "bleed" due to thermal degradation of the chromatographic stationary phase and incomplete removal of solvent (used to recover products from the U-tubes) prior to combustion. Both of these sources were likely to introduce old (i.e., ${ }^{14} \mathrm{C}$-free) carbon to the sample, since it is probable that the solvent $\left(\mathrm{CH}_{2} \mathrm{Cl}_{2}\right)$ and stationary phase derive from petroleum products.

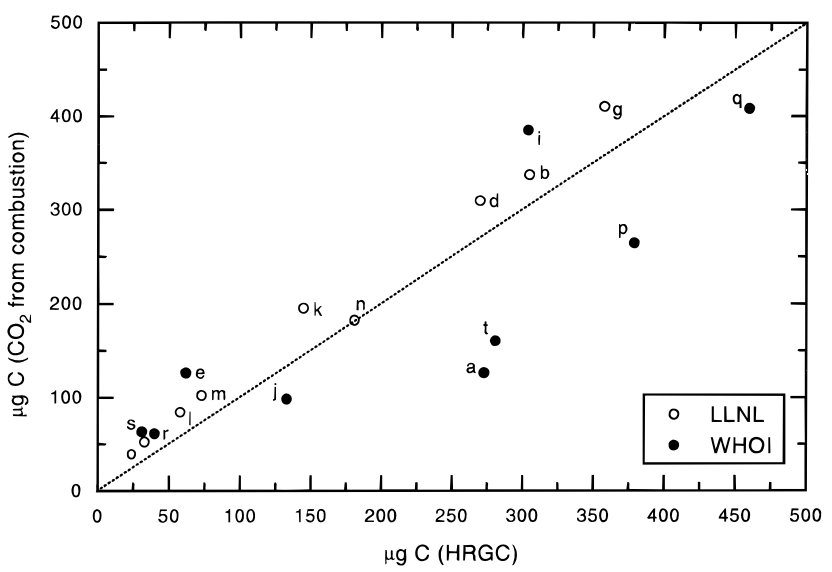

Figure 8. Plot of compound yields (as $\mu \mathrm{g}$ of C) from PCGC estimated by HRGC (peak area) versus combustion (manometric measurement of $\mathrm{CO}_{2}$ ). Open symbols represent samples processed at CAMS-LLNL; closed symbols represent samples processed at NOSAMS-WHOI. Solid line represents 1:1 curve. See Table 2 for compound identification.

During our preliminary investigations using high-capacity, thicker film (>1 $\mu \mathrm{m}) \mathrm{GC}$ columns, we observed significant proportions of methylsilicone degradation residues in the HRGC traces from the U-tube traps, particularly for high boiling compounds. Subsequently, we adopted columns with thinner films of stationary phase $(\leq 0.5 \mu \mathrm{m})$, and, as a result, bleed problems have been greatly reduced. We now estimate the blank resulting from this source to be substantially less than $5 \mu \mathrm{g}$ of $\mathrm{C}$ (based on HRGC data).

The carbon contribution due to incomplete removal of solvent prior to combustion is more difficult to assess because it cannot be monitored by HRGC. As an approximation, we compared compound yields calculated from HRGC peak areas to yields of $\mathrm{CO}_{2}$ produced by combustion of the trapped and dried sample (Figure 8). Although there is reasonable correlation between these two completely independent estimates, we observe considerable scatter, which is likely due to either or both of the following. First, HRGC yields of compounds were calculated relative to an external standard ( $n-C_{28}$ alkane). These estimates are susceptible 
to variations in injection volume, which can vary by $\pm 20 \%$ and to differing FID response factors for different compound types. Second, the scatter could be due to incomplete and variable removal of solvent prior to combustion. We attribute lower estimates from combustion to be due to evaporative loss (during $\mathrm{N}_{2}$ blow-down or evacuation) of volatile compounds. Closer scrutiny of Figure 8 reveals that, typically, the higher boiling compounds and, most notably, $n$-alkanes above $n-C_{20}$ display the most elevated combustion-derived yields. These compounds tend to form a viscous "skin" above the solvent during $\mathrm{N}_{2}$ blow-down, potentially resulting in incomplete removal of the latter.

Stable carbon isotopes can also assist in resolving potential carbon contributions. The stable carbon isotopic composition of an aliquot of the $\mathrm{CO}_{2}$ from combustion of the sample could be compared to that of the trapped compound as determined by irm$\mathrm{GC} / \mathrm{MS}$. Provided the isotopic compositions of the solvent and selected analyte differ sufficiently, $\delta$ values from irm-GC/ M S that do not agree with those from bulk combustion would imply either the presence of residual solvent or other material or that fractionation has occurred.

Since the petroleum hydrocarbons have an infinite radiocarbon age $\left(\Delta^{14} \mathrm{C} \approx-1000 \%\right.$ ) and any ${ }^{14} \mathrm{C}$ recorded must be of foreign origin, the Green River sample provides an opportunity to assess modern $\mathrm{C}$ contamination sources. Examination of Table 2 clearly suggests that modern $C$ contamination is not significant because ${ }^{14} \mathrm{C}$ abundances for corresponding $\mathrm{n}$-alkanes are within the practical limit of the AMS measurement for small samples.

The plant sample $\mathrm{C}$. argentea, used as a source of $n$-alkanes, gave unexpected results given its anticipated "modern" signature. Both the total plant material and individual hydrocarbons yielded surprisingly depleted ${ }^{14} \mathrm{C}$ contents (Table 2 ). No solvent was used to obtain the former value, and sample size was not limiting, so contamination was ruled out. We believe that the ${ }^{14} \mathrm{C}$ contents betray the growth history of this particular plant specimen. The sample was obtained from a local commercial greenhouse which is heated by burners fueled with natural gas. Although the exhaust is vented to the outside, the design provides an opportunity for fumes to enter the greenhouse interior. We conclude that the $\mathrm{C}$. argentea plant has therefore been exposed to $\mathrm{CO}_{2}$ derived from both atmospheric and fossil fuel sources and has fixed this $\mathrm{CO}_{2}$ during photosynthesis, giving rise to the anomalously old ${ }^{14} \mathrm{C}$ ages observed.

The A. americana extract and Egyptian oil sample contain compounds which require derivatization to adjust their polarity/ volatility prior to gas chromatographic separation. The derivatization adds carbon to each compound, which must be corrected for. For fatty acids, one carbon is added to form the corresponding methyl ester during transesterification, and for sterols and other alcohols, three carbons are added to form trimethylsilyl ethers. It has been previously demonstrated ${ }^{23}$ that an isotopic mass balance approach can be applied to determine the stable carbon isotopic composition of the parent biomarker compound, provided the isotopic compositions of the derivative carbon and the total (derivatized) molecule are known. For our purposes, we have adopted a similar approach for $\Delta^{14} C$, the resulting equation being

$$
\Delta_{\mathrm{B}}=\frac{\Delta_{\mathrm{BD}}-\left(\mathrm{f}_{\mathrm{D}} \Delta_{\mathrm{D}}\right)}{\mathrm{f}_{\mathrm{B}}}
$$

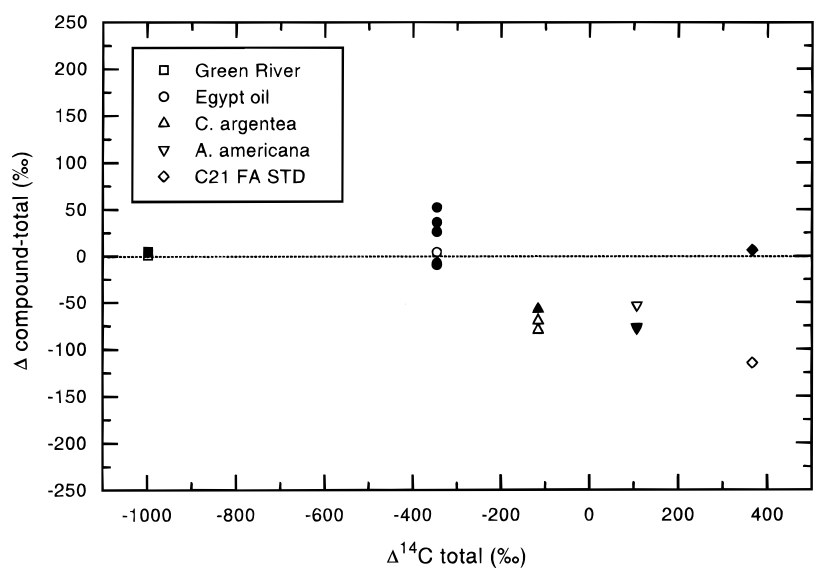

Figure 9. Plot of the difference between $\Delta^{14} \mathrm{C}(\%)$ values for individual compounds and corresponding total (parent) materials (i.e., $\Delta \Delta^{14} \mathrm{C}$ compound minus $\Delta^{14} \mathrm{C}$ total, \%o) as a function of $\Delta^{14} \mathrm{C}$ total for samples studied. Open symbols represent samples processed at CAMS-LLNL; closed symbols represent samples processed at NOSAMS-WHOI. The dashed line indicates perfect agreement between these independent measurements. $\Delta^{14} \mathrm{C}$ values for compounds isolated from the Egyptian oil and $A$. americana samples, in addition to the $\mathrm{C}_{21}$ fatty acid standard, have been corrected for derivative carbon.

where $\Delta_{B}, \Delta_{B D}$, and $\Delta_{D}$ are the $\Delta^{14} C$ values for the parent biomarker (underiviatized), the derivatized molecule, and the derivative carbon atom(s), respectively, and $f_{B}$ and $f_{D}$ are the fractions of parent (biomarker) carbon and derivative carbon in the derivatized molecule.

We have assumed a $\Delta^{14} \mathrm{C}$ value of $-1000 \%$ for derivative carbons $\left(\Delta_{\mathrm{D}}\right)$ since the derivatizing agents (methanol and Regisil) clearly originate from refined petroleum products (Table 1 ). Table 2 lists calculated $\Delta^{14} \mathrm{C}$ values and corresponding ${ }^{14} \mathrm{C}$ ages for compounds isolated by PCGC from the A. americana and Egyptian oil samples both before and after applying this correction for derivative carbon. It is clear that this correction brings the individual compounds into closer agreement with the bulk sample. With respect to the $A$. americana sample, all compounds yield greater-than-modern ages (after correction), which is consistent with the bulk material and the history of this plant. Unlike the C. argentea, the A. americana sample was collected from an outdoor location ( $\mathrm{La}$ Jolla, CA) and was subjected to far lower (if any) fossil fuel $\mathrm{CO}_{2}$. The ${ }^{14} \mathrm{C}$ age of the bulk Egyptian oil sample agrees reasonably well with the historic date of the grave from which it came. The ${ }^{14} \mathrm{C}$ ages for the individual compounds isolated in this sample closely bracket that of the bulk sample.

The difference between $\Delta^{14} \mathrm{C}$ values for individual compounds isolated by PCGC and those for corresponding total materials is plotted in Figure 9. Agreement between the bulk and molecular level measurements, as well as between AMS laboratories, is generally reasonable, with a maximum deviation of $<10 \%$ of the $\Delta^{14} \mathrm{C}$ scale (i.e., $\leq 100 \%$ ). The two youngest samples, $\mathrm{C}$. argentea and $A$. americana, as well as one of the measurements for the $\mathrm{C}_{21}$ fatty acid, deviate most significantly from zero, and, in each case, the individual compounds yield more depleted $\Delta^{14} \mathrm{C}$ values. We estimate the error associated with AMS measurements of small sample sizes $(\sim 25 \mu \mathrm{g})$ to be between 1 and $2 \%{ }^{28,29}$ Based

(28) Klinedinst, D. B.; M cNichol, A. P.; Currie, L. A.; Schneider, R. J .; Klouda G.A.; von Reden, K. F.; Verkouteren, R. M.; Jones, G. A. Nucl. Instrum. M ethods Phys. Res. 1994, B92, 166. 
on $\delta^{13} \mathrm{C}$ measurements, we estimate the maximum error in $\Delta^{14} \mathrm{C}$ due to isotopic fractionation during compound isolation to be $\sim 1 \%$ Assuming that the $\Delta^{14} \mathrm{C}$ values for the compounds and parent materials should be identical we conclude, therefore, that the remaining error $(\sim 7-10 \%)$ is due to contaminating carbon from either column bleed or, more likely, residual solvent. We favor the latter explanation because comparison with Figure 8 reveals that those compounds showing the greatest deviation from equality are typically those which also show elevated combustion-based yields. Despite these minor discrepancies, the relationship shown in Figure 9 implies that, for these internally isotopically homogeneous samples, the compound-based ${ }^{14} \mathrm{C}$ abundances could be used to determine the age of the parent material.

Finally, the data for the $\mathrm{C}_{21}$ fatty acid standard provide an important opportunity to assess the validity of recovering compounds with variable and distinct radiocarbon signatures within a heterogeneous matrix. The underivatized standard gave a $\Delta^{14} \mathrm{C}$ value of $+366 \%$ (Table 1 ). The same compound was spiked into the Egyptian oil sample, esterified, and subsequently isolated by PCGC, along with compounds indigenous to the sample. Excluding the lower value for the fatty acid (for the reasons discussed above), the $\Delta^{14} \mathrm{C}$ value for the standard after recovery from the oil sample (and after correction for derivative carbon) agrees well with that for the starting material and is in marked contrast to the radiocarbon signatures of compounds that constitute the oil (Figure 9). This result demonstrates that compounds can be isolated from mixtures while retaining their radiocarbon signatures.

Taken together, these results demonstrate that the combined advantages of AMS and PCGC provide an opportunity to realize the important technological and scientific goal of compoundspecific radiocarbon analysis (CSRA). Further improvements in the methodology are clearly desirable in order to minimize the error and to provide more precise radiocarbon data, and these efforts should focus on reduction and quantitation of carbon contamination (residual solvent). Nevertheless, it is already apparent that natural abundance ${ }^{14} \mathrm{C}$ measurements are feasible. $M$ any scientific fields could potentially benefit from this development. For example, separate radiocarbon measurements on individual polycyclic aromatic hydrocarbons within environmental matrices would allow distinction between wood and fossil fuel combustion products - a major challenge in pollution-related studies. Isolation of compounds indigenous to an archeological sample would remove potential uncertainties in radiocarbon dating due to interference from impregnation by foreign matrices. Discrimination of natural flavors and aromas from artificial counterparts based on radiocarbon contents (assuming a petrochemical origin for the latter) would also be feasible.

(29) M cNichol, A. P. Unpublished results.

\section{CONCLUSIONS}

From the preliminary experiments conducted to date, we have established the following:

(1) Using PCGC, it is possible to isolate $>250 \mu \mathrm{g}$ of $\mathrm{C}$ of an individual compound from repeated injections of a sample mixture.

(2) The excellent reproducibility of retention times allows narrow tolerances to be applied to the time windows for compound trapping. As a result, the peak purity (as determined by highresolution GC) of isolated compounds can be high (typically $\gg 90 \%$.

(3) There is minimal ${ }^{14} \mathrm{C}$ background contamination ( $\ll 5 \mu \mathrm{g}$ of C) introduced by the PCGC system or by the GC column.

(4) Incomplete removal of solvent prior to combustion is the major potential source of carbon contamination.

(5) Compound-specific stable carbon isotopic analyses of selected analytes indicate minimal isotopic fractionation $(<5 \%$ $\delta^{13} \mathrm{C}$, equivalent to $<10 \%{ }_{0} \Delta^{14} \mathrm{C}$ ), provided compounds are trapped in their entirety.

(6) For compounds which require derivatization prior to chromatographic separation (e.g., fatty acids, sterols), an isotopic mass balance approach can be applied to correct for the carbon atoms added, provided the ${ }^{14} \mathrm{C}$ content of the derivative $\mathrm{C}$ is known.

(7) Initial AM S measurements of compounds isolated from a variety of samples yield ${ }^{14} \mathrm{C}$ contents which are in good agreement $( \pm 10 \%$ ) with the bulk host material and with the sample history.

\section{ACKNOWLEDGMENT}

We thank Dr. M . Kashgarian and other members of the CAM S facility at LLNL, and the NOSAMS facility at WHOI for AMS measurements. Drs. M. Fowler (ISPG, Canada) and R. Carlson (Chevron) are thanked for the petroleum samples. Prof. J. J. Boon (FOM Institute, The Netherlands) is thanked for donating the Egyptian oil sample. We thank Dr. M. A. Goñi (WHOI) for assistance with the irm-GC/M S analyses and useful discussions. M r. C. G. Johnson is gratefully acknowledged for performing the GC/M S analyses. Prof. J. M. Hayes (Indiana University) and Dr. B. Fry (MBL) are thanked for providing access to irm-GC/M S instrumentation. We thank M r. J. Schaap (Gerstel) for technical advice, and Ms. E. Bailey is thanked for secretarial assistance. This work has been supported through grants from the Department of Energy Ocean M argins Program (DE-FG02-92E R61428 to T.I.E.) and the National Science Foundation (OCE -941556800 to T.I.E.). T.I.E. acknowledges financial support from a WHOI Independent Study Award. We also acknowledge support of NSF (OCE -801015) through the NOSAM S cooperative agreement. This is Woods Hole Oceanographic Institution Contribution N 0. 9059.

Received for review August 21, 1995. Accepted December 21,1995 . $^{\otimes}$

\section{AC9508513}

\footnotetext{
${ }^{\otimes}$ Abstract published in Advance ACS Abstracts, February 1, 1996.
} 